\title{
Multi-Resonant Power Converter for Improved Dual-Frequency Induction Heating
}

\author{
H. Sarnago, Member, IEEE, O. Lucía, Senior Member, IEEE, \\ and J.M. Burdio, Senior Member, IEEE.
}

\begin{abstract}
Industrial induction heating is a key manufacturing process due to its benefits in terms of efficiency, accurate output power control, and high performance. These have made possible the extension of this technology to a wide range of industries from automotive to aeronautic, domestic or renewable energies. One of the main challenges still present is the design of a high performance and cost-effective process for those induction targets with complex geometries exposed to the magnetic field, being the most representative example gears present in most mechanical systems. Usually, in order to optimize the heating process, multi-frequency induction heating systems are used, being often expensive and/or difficult to tune and control.

The aim of this paper is, consequently, to propose a family of power converters able to supply the inductor system with two simultaneous frequencies in order to improve the heating process of the induction target. The proposed converter takes advantage of a multi-resonant network allowing full control of the output power delivered at each frequency and, at the same time, a compact and cost-effective implementation. The proposed converter is analyzed, designed and implemented, and experimental verification of its operation is provided in this paper.
\end{abstract}

Keywords - Induction heating, resonant power conversion, home appliances, inverters.

\section{I.INTRODUCTION}

Induction heating $(\mathrm{IH})$ has become the heating technology of choice in many industrial [1, 2], domestic [3] and medical applications [4] due to its benefits in terms of efficiency, accurate output power control and performance, leading to a superior quality process [5]. Regardless the application, IH is based on applying an alternating magnetic field to an induction target to be heated (Fig. 1). The design of the coil as well as the ac source, i.e. power converter,

Copyright (C) 2018 IEEE. Personal use of this material is permitted. However, permission to use this material for any other purposes must be obtained from the IEEE by sending a request to pubs-permissions@iee.org.

This work was partly supported by the Spanish MINECO under Project TEC201678358-R and Project RTC-2014-1847-6, by the DGA-FSE, by the University of Zaragoza under Project JIUZ-2017-TEC-05, and by the BSH Home Appliances Group.

H. Sarnago, O. Lucía, J.M. Burdío are with the Department of Electronic Engineering and Communications, University of Zaragoza, SPAIN (phone: +34976761000, e-mail: olucia@unizar.es).

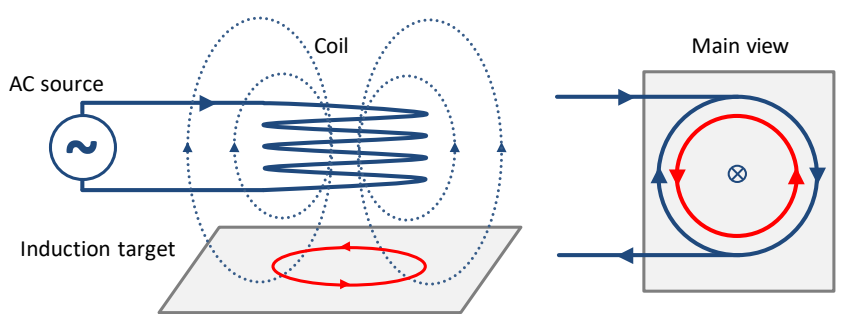

Fig. 1. Induction heating.

must be adapted to the characteristics of the desired process, including the target geometry and temperature distribution, among others.

Modern IH processes require fast heating of complex geometries, including gears for the automotive and aeronautic industries. Heating of such elements requires accurate power delivery at different frequencies in order to provide a homogeneous heating both at the tooth crest and tooth valley to provide superior mechanical properties and prevent unwanted stress.

Dual frequency hardening has been proposed in the past as an efficient method to provide fast and homogeneous heating in target pieces with complex geometries [6]. To achieve this aim, several proposals covered in many patents, papers, and commercial products have been proposed. The main approaches are summarized according to the technology employed in Fig. 2. The first approach is a straight-forward solution proposing one [7] or several inverters supplying 2 IH coils [8,9] (Fig. 2(a)), i.e. each coil has its own inverter. This solution provides an easy implementation but has severe limitations in terms of performance, since the application of the magnetic field is not simultaneous. To overcome this limitation, several manufacturers have proposed simultaneous dual frequency heating using a single coil and two inverters, usually coupled through transformers (Fig. 2(b)) [10-12]. This solution provides better performance, but still presents a significant redundancy due to the use of two independent power converters. Finally, several authors have proposed recently the use of a single power converter to provide

simultaneous dual frequency operation [13-19]. This is a cost-effective solution that provides a higher performance. However, it is difficult to design the resonant tank to be able to control the output power share and to ensure softswitching operation. So the resultant output power control 
and efficiency are limited. Other approaches propose the use of multi-level inverters [20], enabling higher versatility with a more costly and complex implementation. The aim of this paper is to propose a versatile multi-resonant power converter for simultaneous dual frequency IH systems using a single power converter with full output power control and soft-switching operation [21]. Unlike previous proposals, this converter is designed and implemented to operate with a single IH coil, and a wide family of full/half-bridge configurations is proposed, enabling also its operation without requiring coupling transformers. The main advantage of this proposal is the possibility to generate a fully controllable dual-frequency induction heating with a single power converter. Besides, the power converter is designed to be able to operate without isolation transformer and operating under ZVS condition, leading to a high performance and cost-effective implementation.

The remainder of this paper is organized as follows. Firstly, the proposed family of multi resonant converters is presented in Section II. Considering the proposed application, the half-bridge-based implementation is selected, and its detailed operation is analyzed in Section III, which can be extended to the rest of the proposed family. Section IV presents the main implementation and experimental results proving the proper operation during the operation of induction heating a gear and, finally, the main conclusions of this paper are summarized in Section V.

\section{Multi-Resonant CONVERTERS}

\section{A. Proposed topology family}

This paper proposes a family of power converters following the scheme of single-inverter simultaneous-dualfrequency operation to achieve a high performance IH process combining high power density and cost-effective implementation. Fig. 3 shows the proposed topology family based on the use of a multi-resonant network adapted to the IH load, which is modeled as a series inductor and resistor $L_{\mathrm{L}}, R_{\mathrm{L}}$ [22]. The resonant network is composed of a high frequency resonant tank, $C_{r, \mathrm{HF}}-L_{\mathrm{L}}$, and a low-frequency resonant tank, i.e. $L_{\mathrm{LF}}-C_{r, \mathrm{LF}}-L_{\mathrm{L}}$. Fig. 3 summarizes the main implementation including the half-bridge (a), full-bridge (b) and three-phase (c) multi-resonant simultaneous-dualfrequency topologies.

Depending upon the application, the appropriate topology must be selected. Fig. 4 shows a qualitative output power chart comparing the optimum operating regions considering the half-bridge inverter as base topology composed of an inverter branch (IB). On the one hand, a square output power region is obtained if a half-bridge (HB) or full-bridge (FB) topologies are used to feed each frequency range. It is important to note that the maximum output power achievable with the full-bridge topology is 4 times the maximum output power obtained with the halfbridge. On the other hand, asymmetrical regions can be obtained by using a three-inverter-branch (3 IB) converter. One of the main benefits of this implementation consists on the reconfigurability of this solution, that enables the configuration of different output power for each frequency range, depending on the application instantaneous requirements, providing additional flexibility.

Considering a medium power application and for the sake of simplicity, the analysis and experimental results performed in the next sections will be focused on the halfbridge implementation (2 IB), although the main results and conclusions are applicable to the complete proposed family. It is important to note that the proposed analysis can be easily extended to the full-bridge topology, only by considering a bus voltage $2 V_{s}$.

\section{PROPOSED HALF-BRIDGE TOPOLOGY}

The proposed half-bridge simultaneous-dual-frequency topology (Fig. 3(a)) consists of two half-bridge branches, $S_{\mathrm{LF}, 1}-S_{\mathrm{LF}, 2}$ and $S_{\mathrm{LF}, 1}-S_{\mathrm{LF}, 2}$, typically composed of IGBTs, and the multi-resonant network. The resonant networks are composed of the IH load equivalent elements, i.e. $L_{\mathrm{L}}$ and $R_{\mathrm{L}}$, and additional components for the low-frequency and highfrequency tanks. Consequently, the low-frequency tank is composed of $L_{r, \mathrm{LF}}-C_{r, \mathrm{LF}}$, where $L_{r, \mathrm{LF}}=L_{\mathrm{L}}+L_{\mathrm{LF}}$, and the highfrequency tank is composed of $C_{r, \mathrm{HF}}-L_{\mathrm{L}}$. The main advantages of this topology are the use of a single converter, which can be commonly implemented using a reliable IGBT module, the possibility to avoid coupling transformers as well as the use of a common filter-PFC-rectifying unit at the

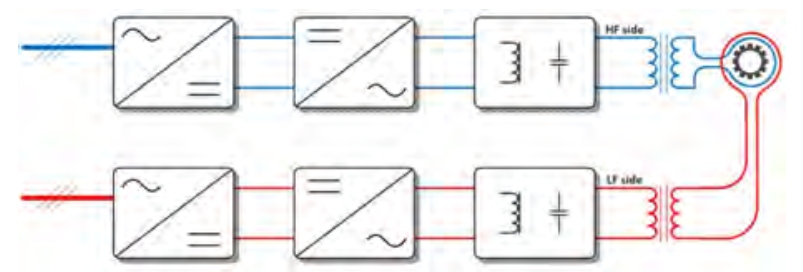

(a)

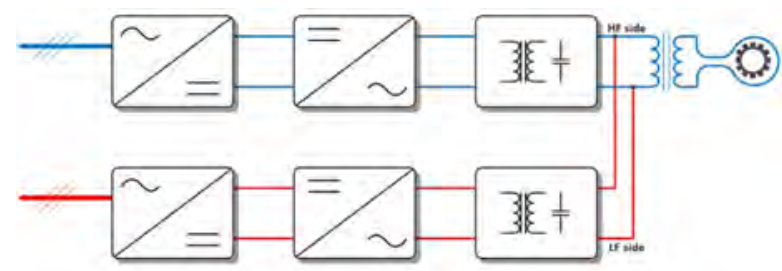

(b)

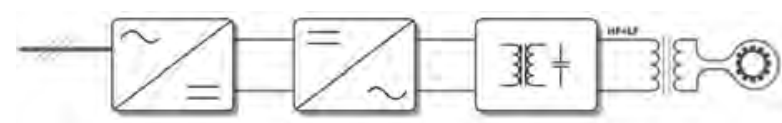

(c)

Fig. 2. Dual-frequency induction heating approaches: (a) two converters and two IH coils, (b) two converters and a single induction heating coil, and (c) a single converter and a single IH coil. 


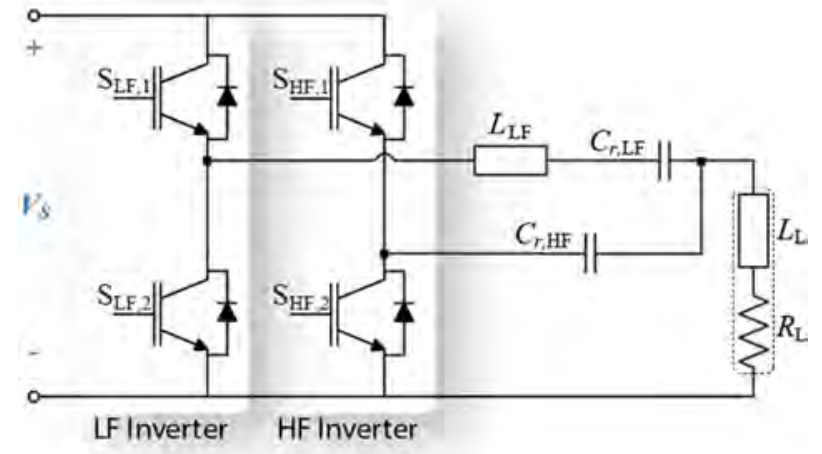

(a)

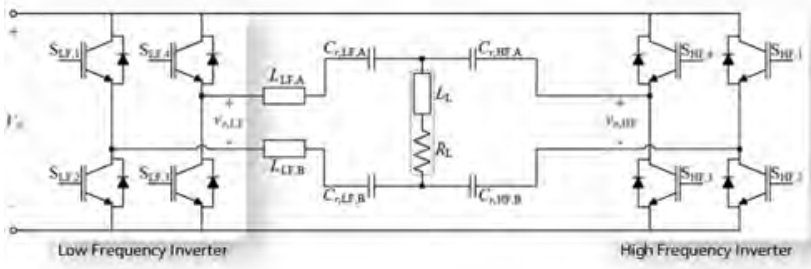

(b)

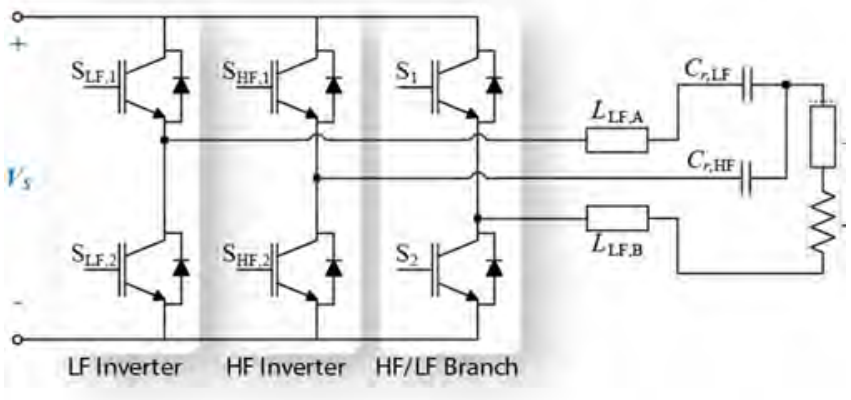

(c)

Fig. 3. Proposed topology family: (a) half-bridge topology, (b) full-bridge topology, and (c) three-phase topology.

input. Besides, as it will be explained in subsequent sections, it is possible to control independently the output power at each frequency to optimize the IH process while achieving soft-switching operation.

\section{A. Operation description}

The equivalent circuit of the proposed half-bridge simultaneous-dual-frequency topology is depicted in Fig. 5, where the inverter branches have been replaced by their equivalent voltage sources. From this figure, it is clear that the output current, $i_{0}$, is the sum of the low-frequency

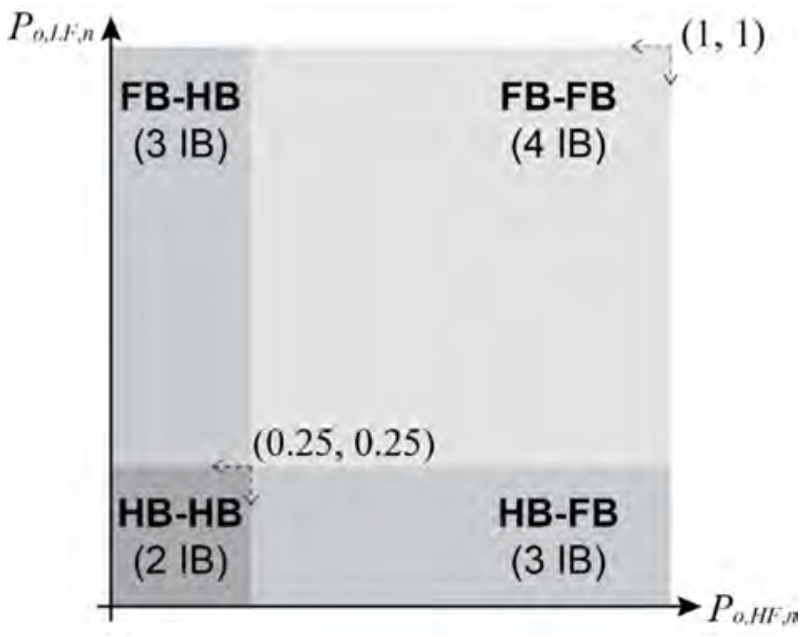

Fig. 4. Output power region comparison of the proposed topologies for each frequency range: half bridge (HB) or full bridge (FB), with the resultant number of inverter branches (IB).

current, $i_{\mathrm{o}, \mathrm{LF}}$, and the high-frequency current, $i_{\mathrm{o}, \mathrm{HF}}$. Fig. 6 shows the main waveforms of the proposed topology, including the output current and a detail of the lowfrequency and high-frequency switching waveforms. It is important to note that both resonant tanks are operated above the resonant frequency, achieving ZVS turn-on transition regardless the operation of the other inverter branch. Besides, the resonant inductor $L_{\mathrm{LF}}$ is designed in order to avoid current cross conduction between the inverter branches. Consequently, the output power delivered at each load can be easily controlled with each inverter branch using either square-wave modulation, asymmetrical duty cycle control [23], pulse density modulation [24-26] or a combination of them [27].

\section{B. Topology analysis}

In order to analyze the proposed topology, the main electrical magnitudes in the power devices and resonant tanks must be obtained. At this point, it is important to note that although the $R_{\mathrm{L}}-L_{\mathrm{L}}$ equivalent $\mathrm{IH}$ load circuit is accepted to be accurate in a certain operating region, these values change with the material temperature and geometry, as well as the excitation frequency, among other parameters.

Indeed, the proposed simultaneous-dual-frequency topology takes advantage of the different magnetic coupling and penetration depth at different frequencies to create the desired thermal profile for the $\mathrm{IH}$ process. Assuming that the resonant tank is designed properly, the low-frequency network impedance will reject any high-frequency current and vice versa. Consequently, the low-frequency and highfrequency resonant tanks can be analyzed independently. Afterwards, and considering that these are linear circuits regardless their frequency dependence, the results can be combined using the superposition principle. 


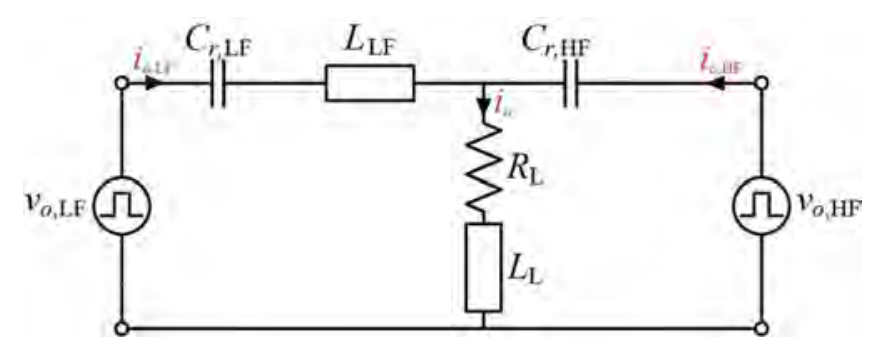

Fig. 5. Equivalent circuit.

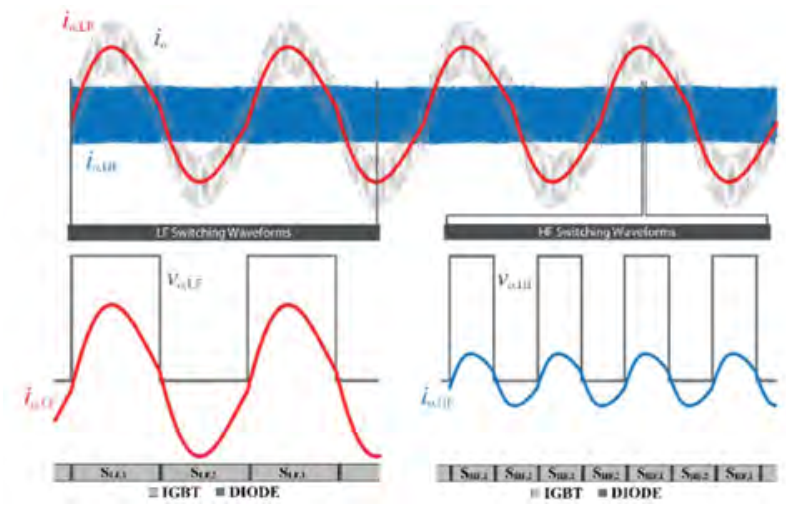

Fig. 6. Main waveforms for the proposed converter topology.

As it has been explained, each one of the resonant circuits can be analyzed independently as a series resonant circuit, where for simplicity equivalent inductors for the low-frequency and high-frequency tanks, $L_{r, \mathrm{LF}}, L_{r, \mathrm{HF}}$, have been defined as follows.

$$
\begin{aligned}
& L_{r, \mathrm{LF}}=L_{\mathrm{LF}}+L_{\mathrm{L}}, \\
& L_{r, \mathrm{HF}}=L_{\mathrm{L}} .
\end{aligned}
$$

Consequently, the differential equation that defines the operation of each resonant circuit is

$$
R_{\mathrm{L}} i_{o, \mathrm{X}}(t)+L_{\mathrm{r}, \mathrm{X}} \frac{\mathrm{d} i_{o, \mathrm{X}}(t)}{\mathrm{d} t}+\frac{1}{C_{r, \mathrm{X}}} \int i_{o, \mathrm{X}}(t) d t=v_{o, \mathrm{X}}(t),
$$

where $\mathrm{X}$ defines the low-frequency (LF) or high-frequency (HF) equivalent resonant tanks, $v_{o, X}$ is the output voltage applied to the resonant tank that equals $V_{s}$ or 0 depending on the switches state. By defining $\xi_{\mathrm{X}}=R_{\mathrm{L}} / 2 L_{r, \mathrm{X}}$ as the damping factor, $\omega_{o, \mathrm{X}}=1 / \sqrt{L_{r, \mathrm{X}} C_{r, \mathrm{X}}}$, as the resonant angular frequency and $\omega_{n, \mathrm{X}}=\sqrt{\omega_{o, \mathrm{X}}^{2}-\xi_{\mathrm{X}}^{2}}$, as the natural angular frequency. Besides, applying the superposition principle, the inductor current will be obtained as

$$
i_{o}=i_{o, \mathrm{LF}}+i_{o, \mathrm{HF}}
$$

The solution of the differential equation can be obtained [28] as

$$
\begin{aligned}
& i_{o, X}(t)=i_{o, X}(t=0) f_{i, X}(t)+v_{c, X}(t=0) f_{v, X}(t)+v_{o, X}(t=0) f_{o, X}(t), \\
& \left\{\begin{array}{l}
f_{i, \mathrm{X}}(t)=e^{-\xi_{X} t}\left(\cos \left(\omega_{n, \mathrm{X}} t\right)-\frac{\xi_{X}}{\omega_{n, \mathrm{X}}} \sin \left(\omega_{n, \mathrm{X}} t\right)\right) \\
f_{v, \mathrm{X}}(t)=e^{-\xi_{X} t}\left(\frac{1}{L_{r, \mathrm{X}} \omega_{n, \mathrm{X}}} \sin \left(\omega_{n, \mathrm{X}} t\right)\right)=-f_{o, \mathrm{X}}(t)
\end{array} .\right.
\end{aligned}
$$

Applying the same methodology, the resonant capacitor voltage, $v_{c, \mathrm{X}}$, can be obtained,

$$
\begin{aligned}
& v_{c, \mathrm{X}}(t)=i_{o, \mathrm{X}}(t=0) g_{i, \mathrm{X}}(t)+v_{c, \mathrm{X}}(t=0) g_{v, \mathrm{X}}(t)+v_{o, \mathrm{X}}(t=0) g_{o, \mathrm{X}}(t) \\
& \left\{\begin{array}{l}
g_{i, \mathrm{X}}(t)=e^{-\xi_{X} t}\left(\frac{1}{C_{r, \mathrm{X}} \omega_{n, \mathrm{X}}} \sin \left(\omega_{n, \mathrm{X}} t\right)\right) \\
g_{v, \mathrm{X}}(t)=e^{-\xi_{x} t}\left(\cos \left(\omega_{n, \mathrm{X}} t\right)+\frac{\xi_{X}}{\omega_{n, \mathrm{X}}} \sin \left(\omega_{n, \mathrm{X}} t\right)\right)=1-g_{o, \mathrm{X}}(t)
\end{array}\right.
\end{aligned}
$$

From these expressions, the output current and resonant capacitor voltages can be computed. Fig. 7 shows the main waveforms and spectral components for different output power distributions. Depending upon the desired output power distribution to perform the required IH operation, amplitudes of low-frequency and high-frequency components are varied accordingly. Moreover, in order to adapt the output currents and, consequently, the output power, the switching frequency of each inverter is slightly modified following its resonance curve.

Assuming that square-wave modulation is applied, i.e. the duty cycle $D_{\mathrm{X}}=0.5$, the maximum output power as a function of the switching frequency $f_{s w}$ [28] for each resonant tank is

$$
\begin{aligned}
& P_{o, \mathrm{X}, D_{X}=0.5}=\frac{V_{s}^{2}}{R_{\mathrm{L}}} \frac{\xi_{\mathrm{X}}}{\pi \omega_{o, \mathrm{X}}} \\
& \left(\frac{\sinh \left(\xi_{\mathrm{X}} / 2 f_{s w}\right)-\xi_{X} / \omega_{n, \mathrm{X}} \sin \left(\omega_{n, \mathrm{X}} / 2 f_{s w}\right)}{\cosh \left(\xi_{X} / 2 f_{s w}\right)+\cos \left(\omega_{n, \mathrm{X}} / 2 f_{s w}\right)}\right) .
\end{aligned}
$$

Consequently, the total output power can be computed as

$$
P_{o}=P_{o, \mathrm{LF}}+P_{o, \mathrm{HF}}
$$




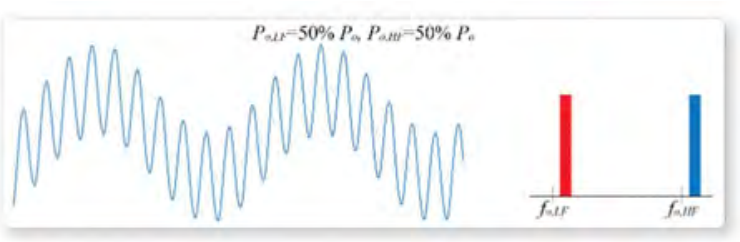

(a)

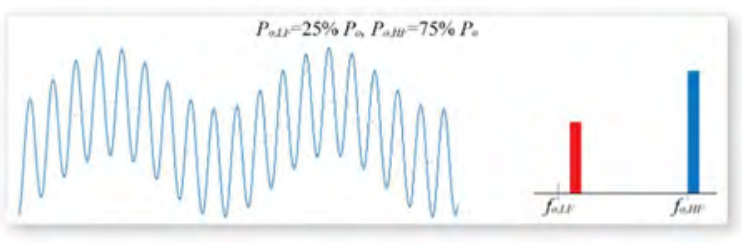

(b)

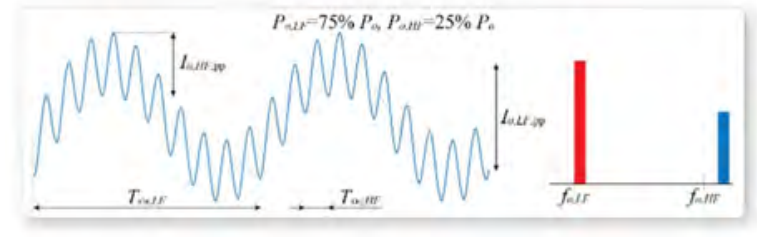

(c)

Fig. 7. Main output current waveforms and spectral components for different output power distributions: (a) $P_{\mathrm{o}, \mathrm{LF}}=P_{\mathrm{o}, \mathrm{HF}}=50 \%$, (b) $P_{\mathrm{o}, \mathrm{LF}}=25 \%$ and $P_{\mathrm{o}, \mathrm{HF}}=75 \%$, and (c) $P_{\mathrm{o}, \mathrm{LF}}=75 \%$ and $P_{\mathrm{o}, \mathrm{HF}}=25 \%$.

At this point, it is important to note that usually the IH process will require to optimize the output power delivered at each frequency as well as the total output power, so a careful knowledge and design of the process is required. Fig. 8 shows an illustrative example of the normalized output current curves for the low-frequency and highfrequency resonant tanks, including the ZVS operation region. From this figure, it is clear that it is possible to control the low-frequency and high-frequency output power/current in a wide range of operating conditions operating under ZVS.

\section{IMPLEMENTATION AND EXPERIMENTAL RESULTS}

In order to prove the feasibility of the proposed topology and experimentally verify its proper operation, a multiresonant half-bridge simultaneous-dual-frequency $\mathrm{IH}$ prototype has been designed and built. A three-phase module IGBT module FS150R12PT5 has been used to provide a versatile test-bench which enables to test all the proposed topology family, as it is shown in Fig. 9. However, for coherence and simplicity, half-bridge experimental results are shown, by using two of the three inverter branches.

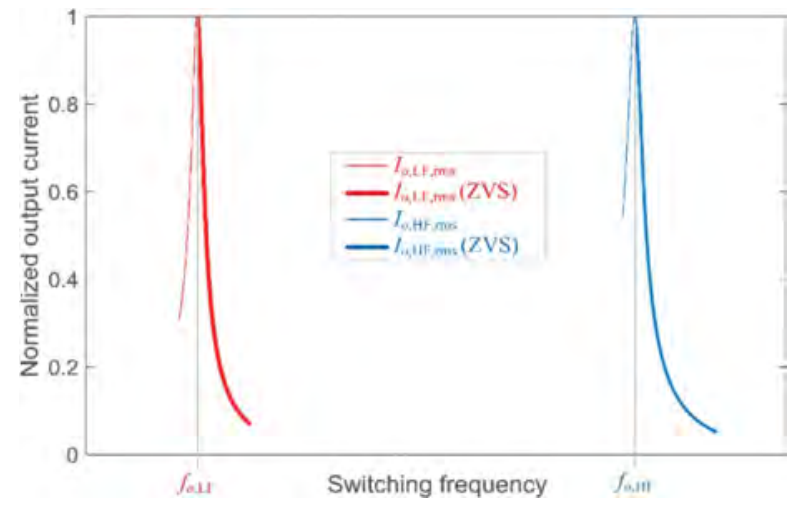

Fig. 8. Normalized output current curves for the low and high frequency resonances.

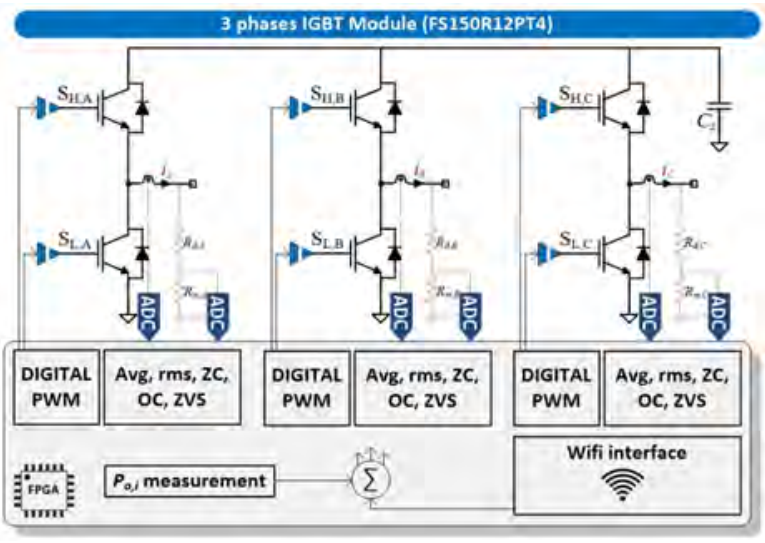

Fig. 9. Experimental test-bench block diagram (two of the three inverter branches are used for the experimental results).

The design parameters are included in Table I. The measured equivalent inductance of the induction heating load results $L_{\mathrm{L}}=1200 \mathrm{nH}$, therefore, the resonant capacitor for the high-frequency side is selected as $C_{r, \mathrm{HF}}=1410 \mathrm{nF}$. In order to decouple the high-frequency and the low-frequency branches, the series inductance has been selected 10 times higher than the one of the IH load, resulting $L_{\mathrm{LF}}=12 \mu \mathrm{H}$. The series resonant capacitor is selected as $C_{r, \mathrm{LF}}=5 \mu \mathrm{F}$. Consequently, the resonant frequencies are set at $20 \mathrm{kHz}$ for the low-frequency resonant tank and $120 \mathrm{kHz}$ for the highfrequency resonant tank, respectively. These values are selected to avoid acoustic noise and enable safe and efficient operation using IGBT technology. Finally, the output transformer is designed to have 30:3 turns using an MPP toroid core and Litz wire to ensure low winding losses.

The power converter uses a versatile FPGA-based control architecture. The output voltage and current of each inverter branch is measured, so the output power, and average and rms values of voltage and currents can be measured for control and protection purposes. After that, independent PI control [29] can be applied to each resonant tank to obtain the desired low-frequency and high-frequency 
TABLE I

EXPERIMENTAL PROTOTYPE SPECIFICATIONS

\begin{tabular}{cc}
\hline \hline Parameter & Value \\
\hline Maximum Power & $1 \mathrm{~kW}$ \\
Switching frequency range & $20-200 \mathrm{kHz}$ \\
Input voltage & $230 \mathrm{~V} \mathrm{rms}$ \\
IGBTs module & FS150R12PT5 \\
$L_{\mathrm{L}}$ & $1200 \mathrm{nH}$ \\
$C_{\mathrm{r}, \mathrm{HF}}$ & $1410 \mathrm{nF}$ \\
$L_{\mathrm{r}, \mathrm{LF}}$ & $12 \mu \mathrm{H}$ \\
$C_{\mathrm{r}, \mathrm{LF}}$ & $5 \mu \mathrm{H}$ \\
LF resonant frequency $f_{\mathrm{f}, \mathrm{LF}}$ & $20 \mathrm{kHz}$ \\
HF resonant frequency $f_{\mathrm{o}, \mathrm{HF}}$ & $120 \mathrm{kHz}$ \\
Output resonant inductor & $2 \times \mathrm{NEL} 64(\mathrm{~N} 87$-gapped) \\
& MPP Toroid 30:3 turns ratio $(\mu=125)$ \\
Output transformer & $(\mathrm{OD}=57.5 \mathrm{~mm}, \mathrm{ID}=26.5 \mathrm{~mm}$, \\
& $\mathrm{HT}=15.2 \mathrm{~mm})$ \\
\hline \hline
\end{tabular}

output powers, according to the desired IH process. Besides, the control architecture takes advantage of a WIFI interface to communicate both settings and measurements to a computer for convenient and safe user supervision.

Fig. 10 shows the experimental prototype, including the power converter (a) and the resonant network and induction coil. The IH coil is built using a 4-turn copper pipe for proper thermal management and the induction heating target is a gear to test the proposed simultaneous-dual-frequency operation. Finally, Fig. 11 shows the main waveforms of the proposed converter, including from top to bottom the output current, the output voltage, and the output current of each inverter branch, high-frequency and low-frequency, respectively. In this figure, different operating points are set to highlight the possibility to control the output power at each frequency in order to obtain the desired IH profile, from maximum power at high frequency (Fig. 11(a)) to maximum power at low frequency (Fig. 11(d)), including several blended modes in between (Fig. 11(b,c)). From these figures it is clear that the proposed converter achieves the desired versatile operation with different output power distributions, while maintaining soft-switching at both inverter branches. Consequently, high control versatility with improved efficiency and reliability is obtained in the whole operating range.

\section{ConClusions}

This paper has proposed a family of power converters suitable for multi-frequency induction heating for improved processes of complex geometry elements. The proposed converter is based on the use of a multi-resonant network which enables simultaneous-dual-frequency operation using a single converter with full control. Compared with state of the art solutions, the proposed converter achieves single-coil single-converter implementation, leading to higher power density, simplicity and reduced cost. Besides, the proposed

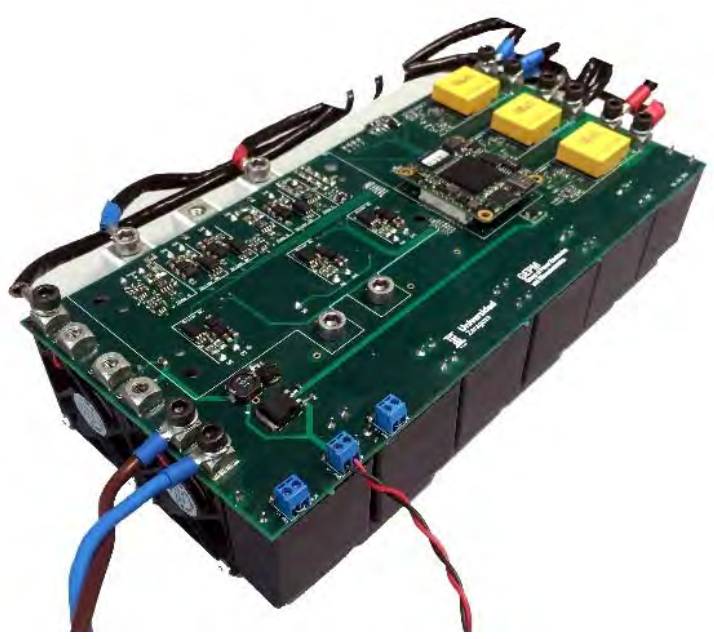

(a)

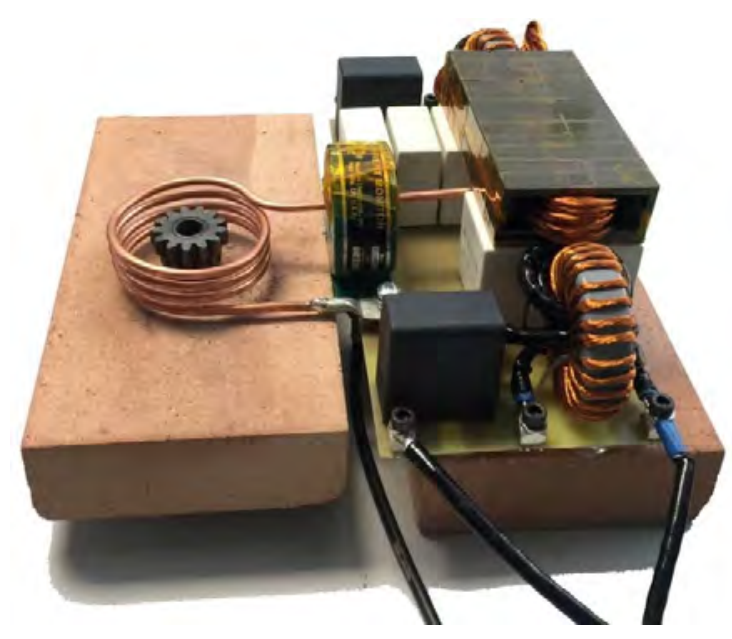

(b)

Fig. 10. Experimental test-bench: (a) power converter prototype and (b) resonant network for dual-frequency induction heating of a gear piece.

converter can control independently the output power delivered at each frequency while maintaining softswitching operation in the whole operating range, providing improved process control and efficiency.

In order to prove the feasibility of this proposal a dualfrequency induction heating prototype has been designed and implemented using the proposed multi-resonant halfbridge topology. The experimental results confirm and prove the advantages of this proposal, guarantying the proper converter operation under a wide range of operating conditions. 


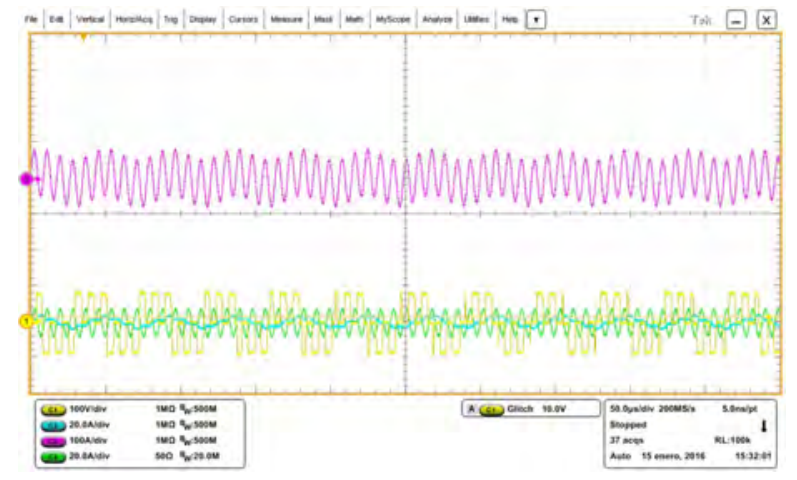

(a)

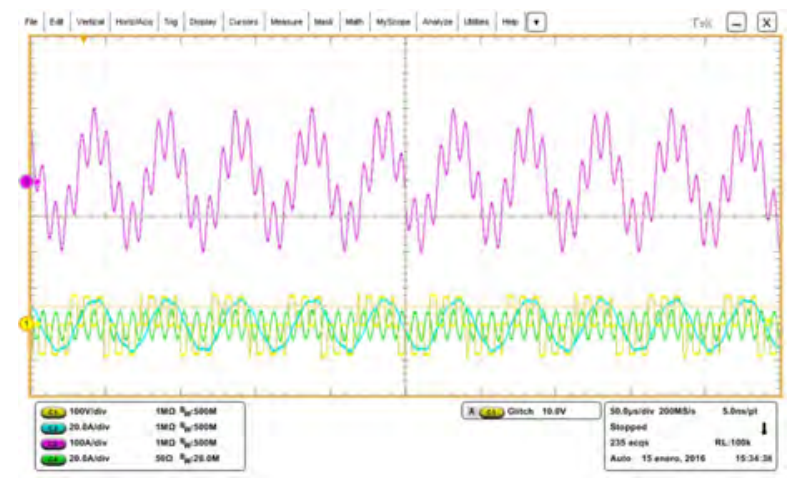

(c)

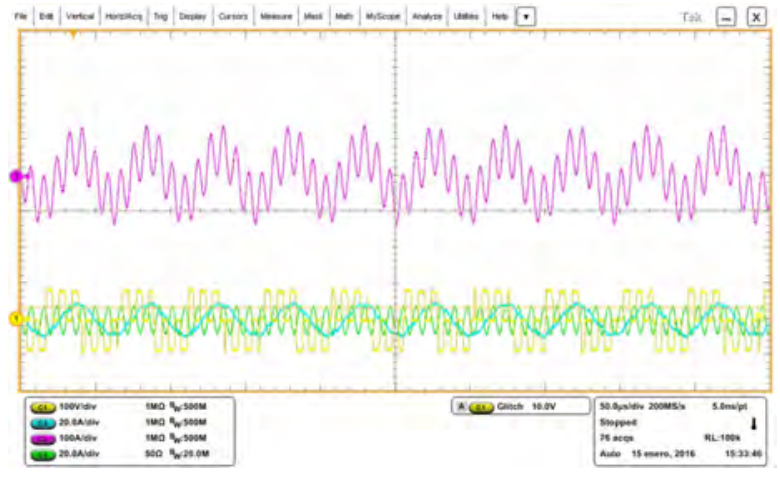

(b)

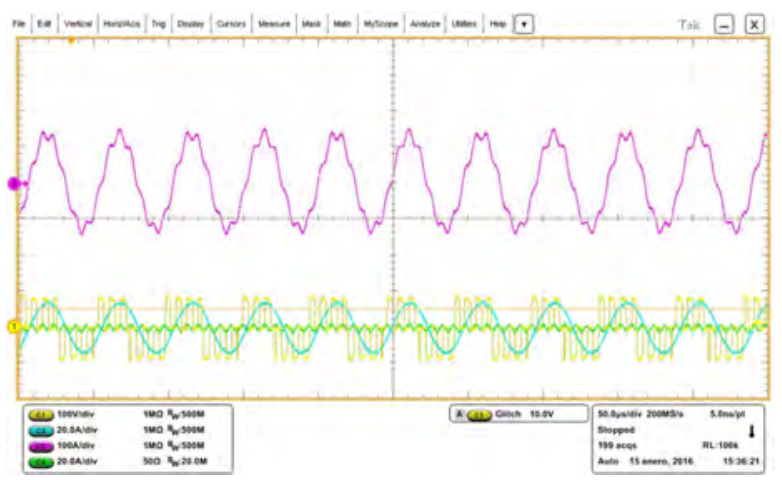

(d)

Fig. 11. Main experimental waveforms of the proposed converter for different high-low frequency balances from full high-frequency (a) to full low-frequency (d). From top to bottom: output current (100 A/div, magenta), output voltage (100 V/div, yellow), low-frequency current $(20 \mathrm{~A} / \mathrm{div}$, cyan) and high-frequency currrent (20 A/div, green).

\section{ACKNOWLEDGMENT}

This work was partly supported by the Spanish MINECO under Project TEC2016-78358-R and Project RTC-20141847-6, by the DGA-FSE, by the University of Zaragoza under Project JIUZ-2017-TEC-05, and by the BSH Home Appliances Group.

\section{REFERENCES}

[1] V. Esteve et al., "Improving the reliability of series resonant inverters for induction heating applications," IEEE Transactions on Industrial Electronics, vol. 61, no. 5, pp. 2564-2572, May 2014.

[2] S. Komeda and H. Fujita, "A Phase-Shift-Controlled High-Frequency Cycloconverter for Induction Heaters," IEEE Transactions on Power Electronics, vol. PP, no. 99, pp. 1-1, 2017.

[3] O. Lucía, J. Acero, C. Carretero, and J. M. Burdío, "Induction heating appliances: Towards more flexible cooking surfaces," IEEE Industrial Electronics Magazine, vol. 7, no. 3, pp. 35-47, September 2013.

[4] P. Di Barba, F. Dughiero, E. Sieni, and A. Candeo, "Coupled field synthesis in magnetic fluid hyperthermia," IEEE Transactions on Magnetics, vol. 47, no. 5, pp. 914-917, May 2011.

[5] O. Lucía, P. Maussion, E. Dede, and J. M. Burdío, "Induction heating technology and its applications: Past developments, current technology, and future challenges," IEEE Transactions on Industrial Electronics, vol. 61, no. 5, pp. 2509-2520, May 2014.
[6] D. Yun, H. Park, J. H. Koo, S. Ham, and S. Lee, "Investigation of Heat Treatment of Gears Using a Simultaneous Dual Frequency Induction Heating Method," IEEE Transactions on Magnetics, vol. 51, no. 11, pp. 1-4, 2015.

[7] W. Han, K. T. Chau, Z. Zhang, and C. Jiang, "Single-Source MultipleCoil Homogeneous Induction Heating," IEEE Transactions on Magnetics, vol. 53, no. 11, pp. 1-6, 2017.

[8] F. S. Serrano, C. Sagues, and S. Llorente, "Power Distribution in Coupled Multiple-Coil Inductors for Induction Heating Appliances," IEEE Transactions on Industry Applications, vol. 52, no. 3, pp. 25372544, 2016.

[9] H. Fujita, N. Uchida, and K. Ozaki, "A new zone-control induction heating system using multiple inverter units applicable under mutual magnetic coupling conditions," IEEE Transactions on Power Electronics, vol. 26, no. 7, pp. 2009-2017, July 2010.

[10]L. Markegard and W. Schwenk, "Method and device for surface hardening of rotation symmetrical parts through inductive heating by means of at least two different frequencies," PTC Patent, 1991.

[11]W. Schwenk, A. Haeussler, and A. Heiliger, "Inductive heating device of workpieces " German Patent, 2003.

[12]L. Markegaard and W. Schwenk, "Method and device for surface hardening of rotation symmetrical parts through inductive heating by means of at least two different frequencies," World Patent, 1991.

[13] V. Esteve, J. Jordan, E. J. Dede, E. Sanchis-Kilders, and E. Maset, "Induction heating inverter with simultaneous dual-frequency output," in IEEE Applied Power Electronics Conference and Exposition, 2006, vol. 1, p. 5 pp. 
[14]J. Jordan et al., "A Comparative performance study of a $1200 \mathrm{~V} \mathrm{Si}$ and $\mathrm{SiC}$ MOSFET intrinsic diode on an induction heating inverter," IEEE Transactions on Power Electronics, vol. 29, no. 5, pp. 2550-2562, May 2014.

[15]E. Dede, V. Esteve, J. Jordan, C. Cases, and J. M. Magraner, "Inductive heating apparatus comprising a resonant circuit with simultaneous dual frequency current output and a single inverter circuit with silicon carbide " EP2148551A1, 2010.

[16] S. Okudaira and K. Matsuse, "Power control of an adjustable frequency quasi-resonant inverter for dual frequency induction heating," in Proceedings IPEMC 2000. Third International Power Electronics and Motion Control Conference (IEEE Cat. No.00EX435), 2000, vol. 2, pp. 968-973 vol.2.

[17]Y. Ishimaru, K. Oka, K. Sasou, K. Matsuse, and M. Tsukahara, "Dual high frequency quasi-resonant inverter circuit by using power MOSFET for induction heating," in 2009 IEEE 6th International Power Electronics and Motion Control Conference, 2009, pp. 25452550.

[18]S. Porpandiselvi and N. Vishwanathan, "Three-leg inverter configuration for simultaneous dual-frequency induction hardening with independent control," IET Power Electronics, vol. 8, no. 9, pp. 1571-1582, 2015.

[19] C. Bi, H. Lu, K. Jia, J. Hu, and H. Li, "A Novel Multiple-Frequency Resonant Inverter for Induction Heating Applications," IEEE Transactions on Power Electronics, vol. 31, no. 12, pp. 8162-8171, 2016.

[20]B. Diong, S. Basireddy, K. Corzine, and Y. Familiant, "Multilevel inverters with equal or unequal sources for dual-frequency induction heating," in Applied Power Electronics Conference and Exposition, 2004. APEC '04. Nineteenth Annual IEEE, 2004, vol. 2, pp. 825-831 vol.2.

[21]H. Sarnago, O. Lucía, A. Naval, and J. M. Burdío, "Convertidor de potencia resonante de frecuencia dual apto para su uso en aplicaciones de calentamiento por inducción," Spanish Patent, 2015. Available: P201630084.

[22]H. Sarnago, O. Lucía, and J. M. Burdio, "A Versatile Resonant Tank Identification Methodology for Induction Heating Systems," IEEE Transactions on Power Electronics, vol. 33, no. 3, pp. 1897-1901, 2018.

[23]O. Lucía, J. M. Burdío, I. Millán, J. Acero, and L. A. Barragán, "Efficiency oriented design of ZVS half-bridge series resonant inverter with variable frequency duty cycle control," IEEE Transactions on Power Electronics, vol. 25, no. 7, pp. 1671-1674, July 2010.

[24] O. Lucía, J. M. Burdío, I. Millán, J. Acero, and D. Puyal, "Loadadaptive control algorithm of half-bridge series resonant inverter for domestic induction heating," IEEE Transactions on Industrial Electronics, vol. 56, no. 8, pp. 3106-3116, August 2009.

[25]V. Esteve et al., "Improving the efficiency of IGBT series-resonant inverters using pulse density modulation," IEEE Trans. Ind. Electron., vol. 58, no. 3, pp. 979-987, March 2011.

[26] H. Fujita and H. Akagi, "Pulse-density-modulated power control of a 4 $\mathrm{kW}, 450 \mathrm{kHz}$ voltage-source inverter for induction melting applications," IEEE Transactions on Industry Applications, vol. 32, no. 2, pp. 279-286, March/April 1996.

[27]N. A. Ahmed, "High-frequency soft-switching ac conversion circuit with dual-mode PWM/PDM control strategy for high-power IH applications," IEEE Transactions on Industrial Electronics, vol. 58, no. 4, pp. 1440-1448, April 2011.

[28]H. Sarnago, O. Lucía, A. Mediano, and J. M. Burdío, "Analytical model of the half-bridge series resonant inverter for improved power conversion efficiency and performance," IEEE Transactions on Power Electronics, vol. 30, no. 8, pp. 4128-4143, August 2015.

[29] O. Jiménez, O. Lucia, I. Urriza, L. A. Barragán, P. Mattavelli, and D. Boroyevich, "An FPGA-based gain-scheduled controller for resonant converters applied to induction cooktops," IEEE Transactions on Power Electronics, vol. 29, no. 4, pp. 2143-2152, April 2014.

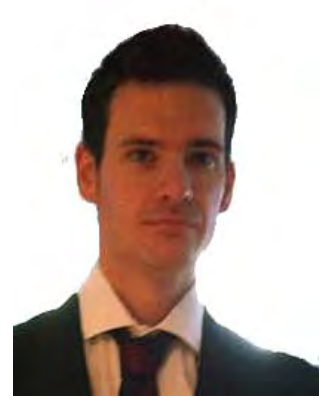

Hector Sarnago (S'09 M'15) received the M.Sc. degree in Electrical Engineering and the Ph.D. degree in Power Electronics from the University of Zaragoza, Spain, in 2010 and 2013, respectively. Currently, he is a senior post-doc researcher in the the Department of Electronic Engineering and Communications at the University of Zaragoza, Spain. His main research interests include resonant converters and digital control for induction heating applications.

Mr. Sarnago is a member of the Aragon Institute for Engineering Research (I3A).

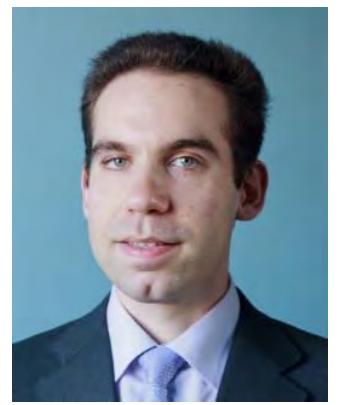

Óscar Lucía (S'04, M'11, SM'14) received the M.Sc. and Ph.D. degrees (with honors) in Electrical Engineering from the University of Zaragoza, Spain, in 2006 and 2010 , respectively.

During 2006 and 2007 he held a research internship at the Bosch and Siemens Home Appliances Group. Since 2008, he has been with the Department of Electronic Engineering and Communications at the University of Zaragoza, Spain, where he is currently an Associate Professor. During part of 2009 and 2012, he was a visiting scholar at the Center of Power Electronics Systems (CPES), Virginia Tech. His main research interests include resonant power conversion, widebandgap devices, and digital control, mainly applied to contactless energy transfer, induction heating, electric vehicles, and biomedical applications. In these topics, he has published more than 60 international journal papers and 125 conference papers, and he has filed more than 35 patent families. Dr. Lucía is a Senior Member of the IEEE and an active member of the Power Electronics (PELS) and Industrial Electronics (IES) societies. Currently, he is an Associate Editor of the IEEE Transactions on Industrial Electronics and IEEE Transactions on Power Electronics. Dr. Lucía is a member of the Aragon Institute for Engineering Research (I3A).

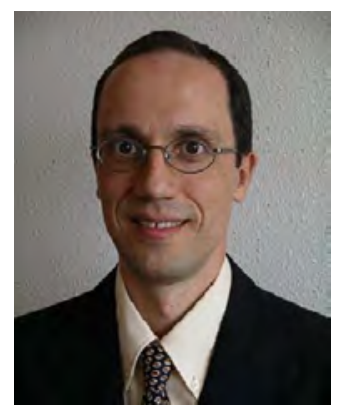

José M. Burdío (M'97-SM'12) received the M.Sc. and Ph.D. degrees in electrical engineering from the University of Zaragoza, Zaragoza, Spain, in 1991 and 1995 , respectively.

He has been with the Department of Electronic Engineering and Communications, University of Zaragoza, where he is currently a Professor, the Head of the Group of Power Electronics and Microelectronics, and the Director of the BSH Power Electronics Laboratory at the University of Zaragoza. During 2000 he was a visiting professor at the Center for Power Electronics Systems, Virginia Tech. He is the author of more than 80 international journal papers and over 200 papers in conference proceedings and the holder of more than 60 international patents. His main research interests include modeling of switching converters and resonant power conversion for induction heating and biomedical applications.

Dr. Burdío is a senior member of the IEEE and the Power Electronics and Industrial Electronics Societies. 